\title{
Developing communication skills in medicine
}

\section{Telling your patient he/she has multiple sclerosis}

\author{
Helen L Ford, Michael H Johnson
}

\begin{abstract}
Summary
It is difficult to tell a person that s/he has multiple sclerosis. The diagnosis is based on clinical findings and often cannot be made on first meeting. In many cases investigations do not help. When the diagnosis is made, the patient should be fully informed in the majority of cases. Guidelines have been developed for imparting the diagnosis. Early diagnosis will become increasingly important with the development of new treatments for multiple sclerosis.
\end{abstract}

Keywords: communication skills, medicine, multiple sclerosis

\section{Making the diagnosis of multiple sclerosis}

Multiple sclerosis is probably one of the most feared diseases to affect young and middle-aged adults. Making and communicating the diagnosis is, therefore, crucially important.

The historical name for the disease 'disseminated sclerosis' reminded us that in order to make the diagnosis, there had to be evidence of lesions occurring in different parts of the nervous system at different points in the history. By definition, therefore, the diagnosis can hardly ever be made at the time when the first symptoms occur. There are exceptions to this general rule. A young woman with a definite episode of optic neuritis in the past, who now has an internuclear ophthalmoplegia, a pale optic disc with a relative afferent pupillary defect, bladder problems and extensor plantar responses can be confidently told the diagnosis. Another young woman with a sensory disturbance starting in her feet and spreading up to the waist, lasting two to three weeks before starting to recede, has very probably got multiple sclerosis but does not fulfill the diagnostic ciriteria and may need to be investigated to exclude another spinal cord lesion.

An experienced doctor may suspect multiple sclerosis at the first visit in many patients with an episode of neurological disturbance, but it may take some years, if and when a second episode occurs, before the diagnostic criteria are fulfilled and the patient can be confidently told what is wrong. She may then complain that she was kept in the dark all that time. Should the doctor have voiced a suspicion of a frightening disease at the first stage, knowing that some patients would not go on to get the disease-defining second episode? If you ask patients later, many express bitterness that the diagnosis was not discussed, but there are one or two who report that they are glad that the suspicion of the disease was not voiced.

\section{Do investigations help?}

Multiple sclerosis is diagnosed on clinical grounds and it is folly to rely entirely on investigation results. The value of investigations is probably exaggerated and a logical approach is needed. If the patient has a relapsing and remitting condition which could result from a single lesion of the central nervous system (CNS), you need to do a test which demonstrates clinically silent lesions elsewhere. There is not a lot of point in doing visual evoked potentials in someone with optic neuritis but they can be useful in someone with a brainstem or cervical cord syndrome. Magnetic resonance imaging (MRI) can show multiple lesions characteristic of multiple sclerosis which will help to confirm the diagnosis in a young person with purely spinal cord symptoms and signs. The analysis of cerebrospinal fluid (CSF) is probably more useful, and just as sensitive, in someone with symptoms indicating disseminated lesions but with few or no signs. The table demonstrates the influence of positive MRI and/or positive oligoclonal bands on the classification of multiple sclerosis according to the Poser criteria. ${ }^{1}$ The importance of historical and clinical examination findings in classification is evident. A very useful discipline is to ask yourself why you are doing the test and what you will tell the patient if it is $(a)$ positive, $(b)$ negative, or (c) inconclusive.

\section{What should the patient be told?}

\section{POSSIBLE DIAGNOSIS}

Department of Neurology, St James's HL Ford MH Johnson
Patients these days are increasingly likely to have suspected the diagnosis but their fear explicitly. If you are sure that multiple sclerosis is very unlikely, it may be useful to tell the patient that you don't think they have a serious condition such as multiple sclerosis or Parkinson's disease. If you think they might have multiple sclerosis, give the patient every opportunity to voice 
Table The influence of positive MRI and/or positive oligoclonal bands in the CSF on the Poser diagnostic classification of multiple sclerosis

\begin{tabular}{|c|c|c|c|}
\hline $\begin{array}{l}\text { History (no } \\
\text { of attacks) }\end{array}$ & $\begin{array}{l}\text { Clinical } \\
\text { evidence }\end{array}$ & MRI/oligoclonal bands & Poser class \\
\hline 2 & 2 lesions & Clinical diagnosis & Clinically definite multiple sclerosis \\
\hline 2 & 1 lesion & $\begin{array}{l}+ \text { MRI } \\
-M R I\end{array}$ & $\begin{array}{l}\text { Clinically definite multiple sclerosis } \\
\text { Clinically probable multiple sclerosis }\end{array}$ \\
\hline 2 & 1 lesion & $\begin{array}{l}\text { + oligoclonal bands } \\
\text { - oligoclonal bands }\end{array}$ & $\begin{array}{l}\text { Laboratory supported definite multiple sclerosis } \\
\text { Clinically probable multiple sclerosis }\end{array}$ \\
\hline 1 & 1 lesion & + MRI* + oligoclonal bands & Laboratory supported definite multiple sclerosis \\
\hline 1 & 1 lesion & + MRI* - oligoclonal bands & Clinically probable multiple sclerosis \\
\hline 1 & 1 lesion & - MRI + oligoclonal bands & Not diagnostic \\
\hline 1 & 1 lesion & - MRI - oligoclonal bands & Not diagnostic \\
\hline
\end{tabular}

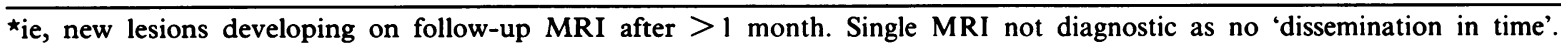

\section{Telling your patient he/she has multiple sclerosis: how not to do it}

A young woman is referred to a neurologist complaining of a numb leg. She goes with her husband for the initial consultation where they are reassured that no serious disease seems to be present. However, the doctor suggests that since they have private medical insurance, it wouldn't hurt to ask for an MRI which would show such things as a thoracic disc.

Two weeks later, the patient, who has by now recovered, goes back on her own to get the result and is told that the scan showed multiple sclerosis. She doesn't recall what was said after that, but had to drive home on her own, collect the children from school, and wait to tell her husband when he comes home. It's a day she is unlikely to forget.

\section{Box 1}

Telling your patient he/she has multiple sclerosis: how not to do it

A middle-aged man develops double vision and is found by an ophthalmologist to have a sixth nerve palsy. After four weeks, it seems not to be improving and the ophthalmologist requests a $C T$ brain scan. The radiology department notice that he is also on their waiting list for an MRI of his lumbar spine where he has some inflammatory problem. They decide to kill two birds with one scan and arrange a brain MRI on the same day. The ophthalmologist reviews the patient, whose double vision has now completely recovered, and reads out the report of the scan which 'diagnoses' multiple sclerosis. The patient now has difficulty getting a mortgage for his business premises even though, three years later, the clinical diagnosis of multiple sclerosis has not been established and he may have some other connective tissue/ inflammatory disorder. their fears. Ask them if they have any thoughts about what might be wrong. Ask if any particular condition worries them. Once they say the dreaded words, it is then much easier to explain whether it is likely or unlikely and to explain what steps may need to be taken to find out. Although most people asked in the street 'Would you wish to be informed if you had multiple sclerosis' would naturally say 'Yes', when it comes to it, there are definite disadvantages to being told. First of all, it may be difficult to get life insurance or promotion at work, the threat of a disabling condition may alter life plans inappropriately, and strains between partners may be introduced. It is as well to point out these potential problems before going ahead with investigations which may not be clinically necessary.

If the patient does not express any concerns that he/she might have multiple sclerosis, you are in much greater difficulty. You can investigate the current symptoms sufficiently to exclude another treatable condition, but if it becomes clear that multiple sclerosis is likely you have to allow time for adequate discussion and sooner or later the diagnosis must be discussed.

\section{DEFINITE DIAGNOSIS}

Most people with multiple sclerosis report dissatisfaction with the way in which they were told they had the disease (see boxes $1-3$ ). They also report anger over the delay in the prompt provision of a diagnosis. In a retrospective survey in Southampton, ${ }^{2}$ approximately $60 \%$ of the population of people with multiple sclerosis felt that they were not given enough information at the time of diagnosis.

Doctors often feel that the diagnosis of multiple sclerosis should be delayed as long as possible to reduce the emotional burden on the patient. However a recent prospective study of people with suspected multiple sclerosis ${ }^{3}$ provides no support for this practice. The health perceptions of people with suspected multiple sclerosis were studied over a six-month period during which time they underwent a diagnostic 'workup'. In those with a definitive diagnosis there was less overall anxiety and less distress about physical symptoms. A further component of the study was to examine the value of diagnostic information to people with suspected multiple sclerosis. ${ }^{4}$ Those patients with a definitive diagnosis reported an increased sense of well-being and a slight improvement in quality of life after diagnosis. However those patients in whom no definitive diagnosis emerged tended to be more anxious rather than reassured by the negative results.

\section{POSITIVE ASPECTS OF DIAGNOSIS}

People with suspected multiple sclerosis have usually had neurological symptoms for some time before presentation to a neurologist. A diagnosis of multiple sclerosis may be reassuring to people fearing they have a brain tumour or that their symptoms are due to mental illness. Patients are thought generally to benefit from earlier diagnosis. ${ }^{5}$

The development of new treatments for multiple sclerosis such as interferon beta-1b, interferon beta-1a and copolymer- 1 has important implications for early diagnosis as these drugs seem to be most beneficial, on present evidence, at an early stage of the disease. ${ }^{6,7}$

\section{Guidelines for imparting the diagnosis $^{8}$}

The British Society of Rehabilitation Medicine with the support of the Multiple Sclerosis Society of Great Britain and Northern Ireland published guidelines for 
Telling the patient he/she has multiple sclerosis: how not to do it

A young woman with vague neurological symptoms is concerned that she may have multiple sclerosis. The neurologist finds nothing definite but requests investigations. The evoked potentials are suspicious and the neurologist tells her that she probably has multiple sclerosis. The next time she comes to the clinic, a different doctor re-examines her and says she probably doesn't have multiple sclerosis. The CSF and MRI are normal, but she still has symptoms and some doctors tell her it is multiple sclerosis while others say it isn't.

Box 3

\section{What do people with multiple sclerosis want to know?}

- general information

- what symptoms might be expected? A working prognosis

- future disability. Will I end up in a wheelchair? Will multiple sclerosis affect my mind? Will I be able to work? Will I die of it?

- is there any treatment?

- what causes multiple sclerosis?

- will it affect my children? Implications for future pregnancy

- self-help measures: suitable activities, exercise, diet

- contact groups: Multiple Sclerosis Society

Box 4

\section{Guidelines for imparting the diagnosis of multiple sclerosis}

- people with multiple sclerosis expect a clear explanation for their symptoms which in the vast majority of cases involves communicating the specific diagnosis to the patient

- many people prefer a relative or friend to be with them

- the doctor giving the diagnosis must have adequate knowledge of the disease and adequate time

- it is thought to be helpful for the doctor to give a 'working prognosis' for the next 12 months

- a follow-up appointment to see the doctor who has discussed the diagnosis should be offered

- information should be given about the local Multiple Sclerosis Society supplemented by appropriate written information about the disease imparting the diagnosis of multiple sclerosis in April 1993 (see box 5). These guidelines were based on information from retrospective surveys of people with multiple sclerosis.

Don't forget that others also 'suffer' from the diagnosis; ask the patient what he/she wants to tell his/her family. Children in particular may have unwarranted fears about the condition.

It may be useful if a specialist nurse is able to talk to the patient as she can provide valuable counselling without the time constraints of an outpatient clinic. Written information or specialist video films can be of great benefit for patients to refer to at home. It is essential that an early follow-up appointment is made so that the patient has a chance to ask questions in a calmer state of mind.

The Multiple Sclerosis Society and other self-help groups can provide support and information, but this should not be rushed. Well-meaning relatives or friends or professionals may overload the patient with advice and information, and a visit to a local branch of the Multiple Sclerosis Society may be a depressing experience for a newly diagnosed patient.

Counselling can be helpful but it is not a simple solution. Somebody with training and experience in communicating 'bad news' may be able to help the patient go through processes akin to a bereavement reaction. Even a very experienced neurologist cannot predict the course or severity of a patient's disease and investigations are of very little help in predicting the future course of the disease.

\section{What information can we give?}

Multiple sclerosis is a chronic neurological disorder affecting one person per thousand of the UK population. The cause is unknown. At present there is no medical cure, although there are treatments which can help many of the symptoms.

\section{COURSE OF MULTIPLE SCLEROSIS}

The course of multiple sclerosis is different in each individual and can be difficult to predict. Initially the disease may be relapsing and remitting with full recovery between relapses. The length of relapse varies greatly between 24 hours and 12 months. ${ }^{9}$ The annual relapse rate varies widely in different studies from 0.1 to 1.15 relapses per year. ${ }^{10}$ Relapse is more common in the first five years after onset and particularly in the first year.

The disease may become progressive at any time after the onset. Secondary progression occurs in about $40 \%$ of patients by 10 years after onset and in $60 \%$ by 15 years. Progression is not, however, inevitable. McAlpine states that in any series of patients seen soon after onset $33 \%$ will be benign at 10 years, $25 \%$ at 15 years and $20 \%$ at 20 years. ${ }^{10}$ Primary progression from the onset of the disease seems to occur in $10-20 \%$ of cases. There is a clear relationship between progressive disease and late age of onset.

\section{EMPLOYMENT}

In the first five years from onset different authors have found that up to $50 \%$ of patients were in full work and up to $70 \%$ were capable of some work. By 15 years between $10-25 \%$ were in full work with up to $40 \%$ of long-term survivors capable of some useful activity. Spastic paresis of the legs is the major cause of the loss of ability to work. Incoordination, sphincter disturbance and fatigue are also significant factors with many patients having more than one disability. More patients could work if there were better access to the workplace or if they could work from home.

\section{LIFE EXPECTANCY}

The degree of disability at any given time is the strongest indicator of life expectancy. The cause of death is not usually a direct effect of multiple sclerosis but results from infective complications or from unrelated disease. Life expectancy for people with multiple sclerosis has been found to be only about 6 to 7 years less than the insured population without multiple sclerosis from the ages 20 to 50 and this difference is even less after age $50 .{ }^{11}$ Many individuals live a normal lifespan.

\section{AETIOLOGY}

The cause or causes of multiple sclerosis are not known. There is evidence that an environmental factor may play a role and that some individuals are more susceptible to this factor and thus more likely to develop the disease. Whether a person will or will not develop multiple sclerosis is thought to have been determined by the age of approximately 15 years. 


\section{PREGNANCY}

There is a slightly increased risk of relapse in some women during the first three months after they have given birth. However the overall course of the disease is not altered by pregnancy. Fertility is not reduced and there is no increased risk of spontaneous abortion or stillbirth. There are no specific complications of labour and no contraindications to breast feeding.

\section{GENETICS}

Multiple sclerosis does occur more commonly in relatives of affected patients than in the rest of the population. Usually only two individuals are affected and the commonest relationship is sibship. The risk of a child being affected is less and is thought to be $1-4 \%$.

\section{SELF-HELF MEASURES}

There is no scientific evidence at present that specific diets alter the course of the disease. The practical results of therapeutic trials involving dietary supplementation with polyunsaturated fatty acids have been disappointing. However, many patients are keen to do something positive themselves and do adapt their diets to include more liquid vegetable fats and unsaturated margarine.

There may be a temporary aggravation or induction of symptoms of multiple sclerosis with exertion. However there is little to suggest that unaccustomed exertion may induce relapse. Common advice is to avoid excessive fatigue but otherwise to continue normal activities.

1 Poser CM, Paty DW, Scheinberg L, et al. New diagnostic criteria for multiple sclerosis: guidelines for research protocols. Ann Neurol 1983; 13: 227-31.

2 McLellan DL, Martin JR, Roberts MHW, Spackman A, McIntosh-Michaelis S, Nichols S. Multiple sclerosis in the Southampton District. University of Southampton: Rehabilitation Research Unit and Department of Sociology and Social Policy, 1989.

3 O'Connor P, Detsky AS, Tansey C, Kucharczyk W. Effect of diagnostic testing for multiple sclerosis on patient health perceptions. Arch Neurol 1994; 51: 46-51.
4 Mushlin AI, Mooney C, Grow V, Phelps CE The value of diagnostic information to patient with suspected MS. Arch Neurol 1994, 51 67-72.

5 Elian M, Dean G. To tell or not to tell the diagnosis of multiple sclerosis. Lancet 1985, 2 $27-8$

6 IFNB Multiple Sclerosis Study Group. Interferon beta- $1 \mathrm{~b}$ is effective in relapsingremitting multiple sclerosis. 1 Clinical results of a multicenter, randomized, controlled trial. Neurology 1993; 43: 655-61.

7 McDonald WI. New treatments for multiple 7 McDonald WI. New treatments
sclerosis. BMF 1995; 310: 345-6.
8 Multiple sclerosis. A working party report of the British Society of Rehabilitation Medicine. April, 1993.

9 McAlpine D, Compston ND. Some aspects of the natural history of disseminated sclerosis. $Q \mathcal{F}$ Med 1952; 21: 135-67.

10 Matthews WB, Compston DAS, Allen IV, Martyn CV (eds) McAlpine's multiple sclerosis, 2nd ed. Edinburgh: Churchill Livingstone, 1991.

11 Sadovnick AD, Ebers GC, Wilson RW, Paty DW. Life expectancy in patients attending multiple sclerosis clinics. Neurology 1992; 42: 991-4. 